\title{
B. Booß-Bavnbek, B. Klösgen, J. Larsen, F. Pociot, E. Renström (eds). BetaSys: Systems biology of regulated exocytosis in pancreatic $\beta$-cells
}

\author{
Springer, New York, 2011, 558 pp (ISBN 978144196955 2). Hardcover US\$209
}

\section{P. Meda}

Published online: 29 July 2011

(C) Springer-Verlag 2011

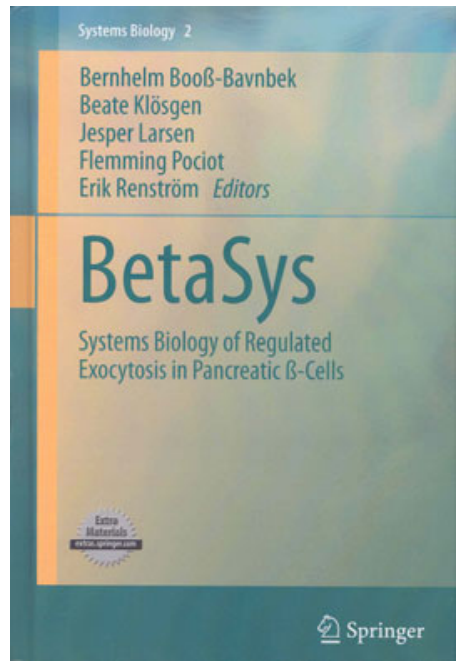

This second volume in Springer's Systems Biology series focuses on the organisation of pancreatic insulinproducing beta cells, with a particular focus on the technological approaches deemed necessary to further our understanding of beta cell physiology and the pathogenesis of diabetes. The book is divided into five parts, which deal with system biology, imaging and sensors, genetics and proteomics, physiological, pharmaceutical and clinical applications, mathematical modelling

P. Meda $(\bowtie)$

Department of Cell Physiology and Metabolism,

University of Geneva,

CMU, 1, Rue Michel Servet,

CH-1211 Geneve 4, Switzerland

e-mail: paolo.meda@unige.ch and numerical simulation. Together, these sections comprise 23 chapters, several of which are written by internationally known experts and cover such diverse themes as the development of beta cells, their structural, genetic, biochemical and physiological organisation, and their relevance to the cell and pharmacological therapy of diabetes. In addition, a variety of state-of-the-art methodsfrom magnetic resonance imaging to bioimpedance spectroscopy - and algorithms for the modelling of substructures and whole body integration of beta cell functions are covered. An interesting feature of the book is that a number of the chapters are introduced by mathematical, physical and chemical considerations, aimed to pave the way for a better understanding of the basic scientific concepts that underlie the biological and clinical observations. Sadly, the chapters contain only a few illustrations, which are of variable quality, and only two chapters contain details of links to online files. The major merit of the book is its attempt to link the many disciplines that have been applied, often in too narrow a way, to address individual levels of beta cell organisation and function. Indeed, a minimal understanding of the limits and advantages of each of these methods is required for a scientist to fruitfully combine several methods in a comprehensive and innovative multi-disciplinary approach. Such a multidisciplinary effort is certainly needed, as many questions about beta cells remain unanswered, in spite of a substantial and costly effort by a wealth of scientists, each of whom has a unique, but possibly too narrow, area of expertise. This new understanding may lead to a paradigm shift, which is needed for better understanding of the beta cell in the context of the ongoing diabetes 
epidemic and the lack of recent major innovations in the treatments available for the disease. Specifically, a multidisciplinary approach could foster a fruitful collaboration between the in silico research and the wealth of experimental and clinical research. A major limitation of this book is its aim to cover a broad spectrum of topics, which may not satisfy the expert yet may still be beyond many graduate and post-doctoral students, who are the primary target market of the publication. This is a minor criticism of this interesting book, which I warmly recommend should be on the shelves of all research laboratories involved in modern beta cell research. 